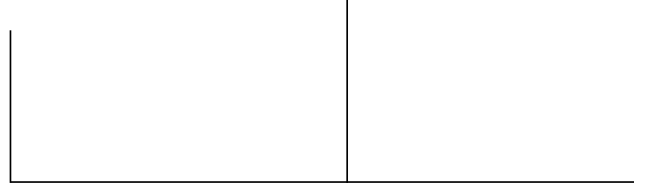

Rev. Latinoam. Psicopat. Fund., V, 4, 170-177

"The place of psychoanalytic treatments within psychiatry - perspectives” Gabbard, G. MD et al Archives of General Psychiatry, v. 59, June 6, 2002. Resenhado por: Débora Siqueira Bueno, Joyce Gonçalves Freire e Tatiana Carvalho Assadi

\title{
Avaliações empíricas de resultados de tratamentos psicanaliticamente orientados - a psicanálise questionada pela psiquiatria
}

Muito se tem falado e escrito sobre o lugar da psicanálise nos dias atuais. Enquanto método, teoria e prática, ela é inapelavelmente convocada a debater sobre esse lugar. Este artigo, com aparição recente nos Archives of General Psychiatry - jornal de grande impacto no campo psiquiátrico - convida os leitores a repensarem a psicanálise no interior da psiquiatria. Escrito por vários autores, encabeçados por Glen Gabbard, psicanalista e renomado pensador da psiquiatria, autor dentre outros de Psiquiatria psicodinâmica (1995) e Treatments of psychiatry disorders (1995) e que escreve freqüentemente pela American Psychiatry Association e na Revista Brasileira de Psicoterapia, o texto questiona este lugar supracitado. O artigo é seguido de três comentários de importantes estudiosos da psicanálise - Otto Kernberg, Robert Wallerstein e Elisabeth Auchincloss - que, discutindo as posições de Gabbard et al., nos colocam a par de como se encontra o atual debate entre psicanálise e psiquiatria no mundo.

No artigo principal, os autores discutem o lugar de tratamentos psicanaliticamente orientados no interior da psiquiatria atual, cada vez mais influenciada pelas neurociências. A argumentação é desenvolvida a partir do pressuposto de que a legitimidade desse lugar deve ser demonstrada, usando-se para tanto os critérios de validação vigentes nas ciências 
empíricas, nas quais o "padrão ouro” corresponde aos ensaios clínicos cujos projetos tenham controle por randomização. Trata-se, portanto, de provar a eficácia e a eficiência destes tratamentos a partir de evidências experimentais.

Embora os autores afirmem a posição de que a psicanálise e as psicoterapias psicanalíticas devam permanecer intrinsecamente integradas ao repertório psiquiátrico de tratamentos, os resultados encontrados nem sempre vão ao encontro desse preceito. Assim, como se estivessem pedindo licença para justificar a presença da psicanálise no arsenal terapêutico psiquiátrico, os autores a apresentam nos seguintes termos:

O tratamento psicanalítico pode ser necessário quando outros tratamentos não são efetivos, ou para problemas residuais, com freqüência menos evidentes, e que persistem após intervenções breves terem feito o seu melhor. As terapias psicanalíticas também possuem o potencial - ainda não testado - de afetar a vulnerabilidade em longo prazo, ao alterar a maneira como o paciente lida com o estresse, conduzindo a mudanças ainda mais consistentes. Este potencial em ser útil para pacientes que não respondem a tratamentos de menor duração autoriza a pesquisa adicional nesta modalidade terapêutica.

Os autores enumeram uma "hierarquia de evidências" que deveria ser seguida como critério para se atribuir valor aos dados que cada estudo encontra, e para que juntos componham uma "estrutura de evidências" quanto ao proveito dos tratamentos psicanalíticos. Estudos que avaliem a eficácia dentro de um "enquadre cuidadosamente controlado, utilizando um tratamento segundo um manual” e que avaliem a efetividade - testes do tratamento em larga escala -, utilizando projetos com controle por randomização, estão juntos no topo dessa hierarquia de evidências. O nível mais baixo nesta hierarquia de evidências consistiria na inovação clínica envolvendo o desenvolvimento de uma terapia com uma fundamentação teórica convincente. Na opinião dos autores, lamentavelmente este seria o único nível de sustentação para a maioria das terapias psicanalíticas.

As dificuldades em se obter dados sobre a eficácia, baseada em estudos clínicos controlados, são tidas como compreensíveis e atribuídas a problemas metodológicos particulares associados à pesquisa da psicoterapia em longo prazo. Entre essas dificuldades são mencionados os custos, a dificuldade em se obter um grupo controle adequado e a presença de variáveis não controladas como doenças, eventos de vida, co-morbidade e mudanças de medicação. A partir deste cenário os autores propõem uma linha para o desenvolvimento de uma estrutura empírica para as terapias psicanalíticas dentro da psiquiatria do século XXI. Ao privilegiar o foco sobre o intrapsíquico, a psicanálise teria se privado da interação entre dados (obtidos a partir de hipóteses testáveis, com observações controladas) e teoria que os autores postulam como necessárias para a ciência moderna. Assim, "tanto defensores como críticos das terapias psicanalíticas serão forçados a repensar o que eles acreditam já saber”. 
Os autores apresentam a proposta de uma agenda de pesquisa em três categorias distintas: treinamento, avaliação padronizada e desenvolvimento de medidas. Em relação ao treinamento, sugerem a inclusão da pesquisa no currículo dos institutos de formação em psicanálise. O objetivo seria promover uma mudança nas atitudes e na infra-estrutura com relação à pesquisa. Uma segunda proposta envolveria a formação de uma base de dados a partir dos tratamentos sob responsabilidade desses institutos. A ausência de um sistema de classificação impediu a construção de uma base de dados cumulativa, portanto, seria necessária a adoção de sistemas de classificação e de diagnóstico operacionalizados para funcionarem em conjunto ou não com o DSM-IV. Em terceiro lugar, deveria ser incentivado o desenvolvimento de um grupo de pesquisadores em psicanálise por meio de um treinamento sistemático, cujos intentos seriam os de medir os resultados por meio de escalas e questionários que avaliassem sintomas, e verificar o tratamento que realmente teve lugar.

Os autores concluem com a proposta de um estudo multicêntrico no qual todos os pacientes submetidos a tratamento psicanalítico sob supervisão se tornariam sujeitos de uma investigação básica sobre a evolução e os resultados desta psicoterapia. Com razoável rigor, estes dados poderiam então oferecer evidências a respeito da efetividade das terapias psicanalíticas e de possíveis diferenças em termos de técnica, tempo de tratamento, tempo e seqüência de mudanças. Sugerem ainda que uma análise de custo-benefício possa ser incorporada, associando a condição clínica à opção de tratamento disponível com o menor custo.

Seguem os comentários anexados a esse artigo publicado pelos Archives, os quais refletem uma primeira repercussão sobre as propostas de Gabbard et al.

Otto Kernberg, Robert Wallerstein e Elizabeth Auchincloss, compartilham da posição dos autores do referido artigo quanto à necessidade de se estabelecer pesquisas padronizadas para a psicoterapia psicanalítica, as quais incitem a clareza quanto aos benefícios e a eficácia desse tratamento.

Otto Kernberg, ex-presidente da International Psychoanalitic Association (IPA), abre o debate sobre o artigo de Gabbard et al. e demonstra um real interesse pelo futuro das contribuições da psicanálise à psiquiatria. As restrições tecidas pelo comentarista são apresentadas em duas vertentes: a escolha de um foco que subestimaria outras contribuições autênticas da psicanálise ao campo da psiquiatria e a limitação excessiva de algumas recomendações. Dentre as contribuições subestimadas estariam o enriquecimento da relação médico-paciente com os conceitos psicanalíticos (transferência, contratransferência, aliança terapêutica) e as contribuições à psicopatologia. Diante da afirmação dos autores de que psicanálise e psiquiatria estariam em um processo de divórcio em função de forças ideológicas, econômicas e políticas, Otto Kernberg questiona se ambas 
deveriam submeter-se passivamente a tais forças ou, partindo de perspectivas científicas e de saúde pública, deveriam questionar os efeitos destrutivos destas forças. A pesquisa baseada em evidências constituir-se-ia num paradigma mais adequado ao estudo de drogas, dando pouca consideração à significância clínica e aos mediadores de uma evolução. A restrição implícita neste enfoque poderia inclusive comprometer o próprio progresso científico. Com relação à hierarquia de evidências, os problemas metodológicos são apontados de forma apropriada, porém o efeito deletério das restrições ideológicas e financeiras nas políticas públicas estaria sendo subestimado ao se priorizar a busca de evidências.

Por outro lado, Kernberg enfatiza a importância do diagnóstico e concorda com os autores que as abordagens de tratamento devam estar sujeitas a um manual ou roteiro para que seja possível a comparação de um grupo experimental com um grupo controle. Ele acredita inclusive na viabilidade do desenvolvimento de manuais para a psicoterapia psicanalítica. Segundo sua opinião, a restrição maior à proposta dos autores estaria na relutância de institutos e sociedades de psicanálise em aderirem a um esforço de pesquisa, pois este esbarraria em resistências históricas, culturais e ideológicas. Não podemos deixar de assinalar que sua defesa quanto à criação de um manual roteirizado para a psicanálise nos causa um estranhamento pelas razões que logo apontaremos.

O comentário de Wallerstein é norteado por três questões: a primeira relativa ao protocolo; a segunda a mensuração e revisão da padronização da eficácia da terapia e a terceira na interface entre teoria, técnica e prática (nomeada como método). Ele adverte o leitor que os protocolos usados nesta mensuração da psicanálise e a comprovação de sua eficácia devem ser, antes de tudo, aqueles que priorizam e medem a dimensão de estrutura da personalidade e não só o sintoma e o comportamento, pontos fundamentais dos protocolos utilizados até então. Sustenta a idéia de que são necessárias revisões e padronizações constantes destes processos avaliativos, mas deixa um rastro, uma questão que parece destruir esta medida da eficácia: como medirmos o problema clínico, as transformações no processo terapêutico e as novas implicações das doenças? Adverte ainda que a psicanálise não é exclusivamente uma terapia, como crêem muitos, é antes de tudo uma técnica e um método de investigação.

Auchincloss considera que os autores não foram longe o suficiente na exploração do lugar do tratamento psicanalítico no interior da psiquiatria, pois não basta uma investigação sistemática baseada em um manual padronizado sobre como trabalhar com a psicoterapia psicanalítica; é incontornável uma pesquisa sobre como trabalha a mente humana. O artigo de Gabbard et al. a seu ver privilegia a pesquisa a respeito da eficácia e da efetividade da psicanálise, voltada para o que entra (in-put) e o que sai (out-put), em especial, às mudanças do comportamento e à evolução do sintoma, sem se deter no processo intrapsíquico, 
já que este é refratário à observação controlada e à hipótese testada. Neste ponto, ela aponta para algumas pesquisas de psiquiatras cognitivistas, os quais buscam aportes na teoria psicanalítica da mente - o processo psíquico - para pensarem sobre questões como a consciência (é bom lembrar que esta foi uma das questões metapsicológicas de Freud), a cognição, a linguagem e de suas interações com o inconsciente. Na opinião dessa comentarista, o lugar da psicoterapia psicanalítica no interior da psiquiatria, de fato dentro mesmo da ciência moderna, está assegurado precisamente porque essa terapia vem anexada a um modelo da mente, o qual não pode ser elidido.

A construção proposta de interlocução crítica entre a psiquiatria e a psicanálise é de extrema valia para a cura dos pacientes com sofrimentos mentais. Contudo, o argumento de Gabbard et al. não contempla aspectos determinantes do tratamento, alguns deles apontados pelos comentaristas, como a transferência, o sintoma não fenomênico e a subjetividade.

Quanto ao sintoma é possível caracterizar que o que está sendo relevante é sua roupagem empírica e não sua estrutura particular. A tendência da amarração proposta pelos autores é de que o sintoma que deve ser tratado é aquele aparente e não um sintoma como formação de compromisso de inconsciente - ponto nodal da psicanálise.

Em relação à transferência, é possível pontuar que esse mecanismo descoberto por Freud encontra-se no âmago das relações intersubjetivas e, no caso especial de um tratamento, este processo psíquico é potencializado e direcionado para a figura do médico/psicanalista. Isto quer dizer que o investimento psíquico, reatualizando as vivências particulares do paciente, é transformado em ódio e amor para o seu médico. Freud ainda revelava o caráter fundamental da transferência como motor e ponto de resistência de qualquer tratamento. Nesse artigo, a questão transferencial não é sinalizada, embora seja tácito que a psiquiatria denominada dinâmica que associa as doenças da alma, dos nervos e do humor, deve levar em conta um tratamento dinâmico do paciente priorizando a relação transferencial médico e doente.

Está aberta a questão de como elaborar um manual roteirizado para o trabalho psicoterápico cujos resultados seriam os mesmos, independente do psicanalista e do paciente. A subjetividade é um dos pontos centrais da clínica. A pesquisa, a teoria e a prática devem ser construídas nas particularidades, nos dramas individuais e que recebem, no conjunto, nas suas similaridades marcas trágicas, universais. A sociedade atual coloca uma tônica no individual, em vez de relevar a subjetividade. O que queremos dizer com individualidade é a liberdade sem interdições, uma história sem pontos de amarração, um excesso e ao mesmo tempo a ausência do desejo, que tende a uma normatização sem freios. É isto que o texto incorpora como manualized - um roteiro de normas padronizado. 
A idéia central do artigo é a de discutir como a psicanálise poderia ser utilizada para ser averiguada em sua existência, e ter comprovada sua eficácia. No entanto, eficácia foi confundida com estatística normativa. Embora os autores neguem postular um retorno aos desacreditados resíduos do positivismo lógico, em nossa impressão é exatamente disto que se trata. Esbarramos aqui em diferenças de natureza ideológica que são incontornáveis, e que, portanto, convocam a um debate que busque oferecer um outro caminho para a questão proposta pelos autores.

A ordem do dia para a psicanálise e para a psiquiatria, então, é pensar de que forma o que pode ser útil aos tratamentos psi não reduz a alma a uma coisa manualized.

\section{Referências}

Quinet, A. (org). Psicanálise e psiquiatria: controvérsias e convergências. Rio de Janeiro: Marca d’Água, 2001.

Roudinesco, E. Por que a psicanálise? Rio de Janeiro: Jorge Zahar, 2000.

“Angústia de separação e angústia de esfacelamento”

Gilbert Diatkine

Revista Francesa de Psicanálise, Tomo LXV, p. 395-408, abril-junho/2001,

Resenhado por: May Guimarães Ferreira de Melo Leitão

\section{Separação e fragmentação do eu}

Viver é separar-se. Sem separação não existe nenhuma possibilidade de desenvolvimento e constituição do sujeito e de sua singularidade. A partir das inúmeras separações vividas ao longo da vida, o indivíduo experimenta uma variedade de sentimentos que podem se transformar em capacidade de integração interna ou em esfacelamento contínuo de si e de seu mundo, tanto interno quanto externo.

A angústia de separação pode ser observada em diversas circunstâncias, universalmente conhecidas, tais como distanciamento do sujeito em relação ao 
objeto amado, a perda dos objetos significativos, que envolvem sentimentos de abandono e a percepção do caráter efêmero da existência e das teias de relações humanas, aos quais pertencem os indivíduos desde antes mesmo do seu nascimento.

Além de poder ser fundamental no processo de constituição do eu, a angústia de separação permeia a constituição da identidade e a capacidade de convivência com o outro e com a realidade.

A capacidade de elaboração das angústias de separação varia de indivíduo para indivíduo, podendo apresentar a possibilidade de ampliação da comunicação consigo próprio e com o outro. Quando este enfrentamento se realiza de maneira muito dolorosa surgem reações como ansiedade, mágoa, pesar, depressão, psicossomatizações diversas, agudas e crônicas, e suicídio. Essas reações são quase sempre inconscientes e acompanhadas de fantasias de perda e de separação, que se confundem mediante o temor da perda definitiva do objeto amado, mesmo em momentos de separações provisórias, sem distanciamento espacial ou temporal.

O artigo intitulado “Angústia de separação e angústia de esfacelamento”, de Gilbert Diatkine, aponta a possibilidade freqüente de transformação da primeira modalidade de angústia, na segunda.

Segundo o autor, muitas pessoas em situação de análise reproduzem as angústias de esfacelamento por ocasião de separações provisórias vividas em análise ou ao final de uma análise, impossibilitando a unificação das pulsões e de seus objetos internos, levando a reações terapêuticas negativas que prolongam a dependência física e psíquica do paciente em relação ao analista.

A partir das memórias do presidente Schreber, tais como discutidas por Freud, o autor ilustra o processo de transformação de angústia de separação em angústia de esfacelamento. A descrição da separação provisória da sua mulher por ocasião de uma viagem de quatro dias, quando ela cessou de visitá-lo diariamente na clínica psiquiátrica onde Schreber se encontrava internado, provocou o agravamento do seu estado psíquico com manifestação do sentimento angustiante de esfacelamento do corpo e aparecimento de delírios. Uma segunda separação significativa, em relação ao psiquiatra Flechsig, aparece quando Schreber é transferido de uma clínica para outra, substituindo-o pela enfermeira chefe e, novamente, outra separação quando vai para uma longa temporada no asilo provincial.

A angústia de esfacelamento aparece no seu corpo e nos seus objetos constituindo, juntamente com os delírios, o quadro psíquico de fragmentação e paranóia daquele psicótico que tanto intrigou a Freud.

$\mathrm{O}$ artigo de Diatkine afirma que Freud, diferentemente de Bleuler, pensa a angústia de esfacelamento como uma regressão que ultrapassa o narcisismo, alcançando até o auto-erotismo. No narcisismo, o investimento está fixado em 
objeto único, o eu, ponto de fixação da paranóia, enquanto que na esquizofrenia o eu é investido como um objeto fragmentado.

Sobre Schreber, Freud descreve a reconstrução de um mundo vivo que produz o delírio, mas não se interessa pela passagem da fragmentação para uma relação de objeto unificado. Enfim, no desenvolvimento normal, o sujeito pode passar de um estado ao outro.

Para Diatkine, seria na obra de Melanie Klein que se encontra a compreensão do processo psíquico necessário para a passagem de uma relação com o objeto fragmentado para uma relação com o objeto unificado.

Uma primeira leitura de Klein poderia esclarecer o que seria a "ação psíquica particular” que permite passar do auto-erotismo ao narcisismo, porém uma leitura mais apurada leva a um impasse pela ausência de explicação acerca do processo de incorporação do objeto bom e da reparação do objeto total. A modalidade de reparação obsessiva repousa sobre o isolamento do objeto e a maníaca separa os objetos e lhes mantém "em um estado de animação suspensa”.

A alternativa alcançada por ela, no contexto dos anos 1940, seria a oposição entre os conceitos de "objeto" e "imago", este compreendido como o objeto real mais as projeções boas ou más, que são elaboradas sobre aquele. Klein introduz, de forma imprecisa ainda, a noção de "substituto" para levar em conta a introdução da mãe exterior, considerando que sua "imagem" substitui os fantasmas dos sujeitos.

Em conclusão, o autor se refere à desagregação da unidade do ideal de ego como capaz de provocar sentimentos de despersonalização e esfacelamento, quando os conflitos internos do superego são de gravidade particular. Para ele, os pacientes que sofrem de angústia de separação intensa passaram por "traumatismos transgeracionais precoces” que podem ser relacionados ao auto-erotismo. Ao citar o caso do bailarino Nijinski, demonstra o sofrimento de abandono e esfacelamento que ele sofria, ao lado da sua genialidade e de seu narcisismo.

Ao findarmos a leitura do artigo de Diatkine podemos apontar a importância da elucidação do tema abordado, não somente no âmbito da psicanálise, mas também, em outros campos do conhecimento socialmente acumulado, como a Filosofia e a Literatura, que pretendem dar conta da "alma", do pensamento e da natureza humana. No discurso de Aristófanes, em $O$ banquete, Platão conta como Zeus encontrou um modo de tornar os homens mais domesticados e servis: dividindo-os em pedaços. No entanto, será Lygia Fagundes Telles, na crônica "Resposta a uma jovem estudante de Letras", que nos pergunta se é possível "recompor" os sentimentos de separação com a capacidade de simbolizar com a palavra escrita: "O escritor escreve porque tenta recompor, quem sabe? Um mundo perdido. (...) Ou não será o próprio eu despedaçado que ele está querendo resgatar?” 